\title{
Evidence for non-existential readings of locative indefinites *
}

\author{
Robert M. Grimm \\ Utrecht Institute of Linguistics OTS \\ Utrecht University \\ Eva B. Poortman \\ Utrecht Institute of Linguistics OTS \\ Utrecht University
}

\author{
Choonkyu Lee \\ Utrecht Institute of Linguistics OTS \\ Utrecht University \\ Yoad Winter \\ Utrecht Institute of Linguistics OTS \\ Utrecht University
}

\begin{abstract}
We report on experimental results which show that sentences involving locative indefinites can give rise to non-existential readings. We are far from a gas station, for example, was judged as false by about two thirds of our subjects in situations where we are close to the nearest gas station, yet there also is a more distant gas station such that we are far from it. We examine two accounts of this kind of reading. Under one possible explanation, far from decomposes into its negated antonym. Under an alternative account, indefinites denote properties which are associated with eigenspaces - the spatial regions inhabited by the entities in the extension of the property. We present new evidence, with experimental support, for the latter account: sentences containing indefinites with projective locatives have a salient false interpretation also in situations where the existential reading is true-and decomposition into negated antonyms fails to explain this. Our results imply that indefinites denote properties first and, through derivational ambiguity, existential quantifiers second.
\end{abstract}

Keywords: indefinite, locative, preposition, spatial semantics, eigenspace

\section{Background}

\subsection{The issue: non-existential readings of locative indefinites}

Iatridou $(2003,2007)$ points out an interpretative contrast with indefinites in locative PPs, as in the following example:

(1) We are far from a gas station.

Under one possible interpretation, (1) means that there exists some gas station such that we are far from it. This existential interpretation stands in contrast to a second,

* The authors wish to thank Joost Zwarts for helpful comments. This work was partially supported by a VICI grant number 277-80-002 by the Netherlands Organisation for Scientific Research (NWO). 
non-existential interpretation. Namely, given an appropriate context, (1) can be interpreted to mean that we are far from all gas stations. For example, suppose we are in a car race through the desert, and we are running low on gas. In that situation, what matters is our distance to the nearest gas station. Thus, if there is some gas station such that we are far from it, yet we are close to the nearest gas station, the sentence is still likely to be interpreted as false. For (1) to be true, we have to be far from the nearest gas station. And if we are far from the nearest gas station, we are certainly far from all other gas stations-i.e., we are far from all gas stations. For (1), then, there are two possible interpretations. Compare this to sentence (2), where far from is replaced by close to:

(2) We are close to a gas station.

For close to, we only get an existential reading: (2) is true just in case there is some gas station such that we are close to it. It does not matter whether, in addition, there also is some far-away gas station.

Deriving the existential reading for (1) and (2) is easily achieved via existential quantification, but it is less clear how to obtain the non-existential reading of (1). With some inspiration from Büring (2007), we may conceive of a derivation which involves decomposing far from into its negated antonym not close to (Mador-Haim \& Winter 2014). Relying on existential quantification, scope ambiguity with respect to negation would then allow us to derive both the existential reading (3) and the reading in (4), which corresponds to the non-existential interpretation:

We are [[not close to] $\mathrm{SOME}_{\exists}$ gas station]

We are [not [close to $\mathrm{SOME}_{\exists}$ gas station]]

Negating the existential quantifier in (4) results in a universal quantifier, which explains the universal effect with the non-existential interpretation of (1). On the reading in (4), that is, We are far from a gas station is true just in case we are far from all gas stations.

But decomposition into negated antonyms fails to derive the required nonexistential reading for projective PPs such as south of or west of, where the nonexistential interpretation shows no such universal effect. Consider sentence (5):

We are south of a forest.

If we are north of the nearest forest, (5) may be interpreted as false. In such a case, there may be some forest such that we are south of it. This is the case in Figure 1, where the two gray shapes are forests, and our position is marked by the cross.

Certainly, the sentence is ambiguous - there is a possible existential interpretation, where we require some forest such that we are south of it, and that would 


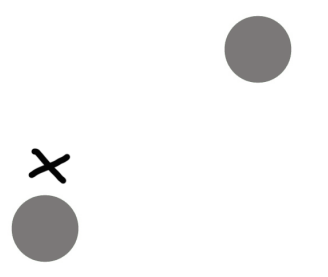

Figure 1 Context where sentence (5) can be interpreted as false.

render (5) true in the context of Figure 1. However, the non-existential interpretation also remains available. This becomes apparent when we make it more accessible by providing a suitable context. For instance, suppose we are explorers looking for a rare kind of bear, and this bear is known to only live in forests. We have been unable to find the bear, and so I check a map. If I now utter (5), the non-existential reading is a likely interpretation, i.e. (5) is false-we are north of a forest, not south of one.

Importantly, decomposition into negated antonyms cannot explain the nonexistential reading of (5). This approach would only give us the readings that (a) there exists no forest such that we are north of it, and that (b) there exists a forest such that we are not north of it. While (b) correctly corresponds to the existential reading, (a) would incorrectly commit us to a reading where (5) is true just in case we are south of every forest. This, however, is not attested among the possible interpretations. What is more, we cannot account for the symmetric effect with north of, which would itself have to be decomposed into not south of. Such a situation did not arise with far from because its antonym close to does not produce the same non-existential effect we see with far from. But because both south of and north of may lead to non-existential interpretations, we run into an infinite regress where each decomposed antonym needs to be further decomposed. ${ }^{1}$

\subsection{A possible solution: the Property Eigenspace Hypothesis}

To better account for non-existential readings of locative indefinites, Mador-Haim \& Winter $(2007,2014)$ suggest a treatment of locative indefinites that is, in essence, a continuation of the semantics of entity-denoting NPs proposed in Zwarts \& Winter 2000. Consider the following sentence, with the referential NP the line inside a locative PP:

(6) The dot is left of the line.

For (6) to be true, it merely needs to be the case that the dot is left of the closest point within the line. If this is the case, then (6) is true even if there is some other

1 See Mador-Haim \& Winter 2014 for additional arguments against the decomposition approach. 


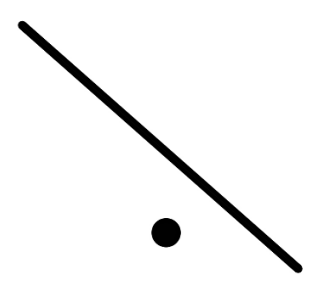

Figure 2 Context where sentence (6) is true, in spite of the dot being to the right of the upper left part of the line.

point within the line such that the dot is to the right of that point. Such a situation is depicted in Figure 2. Clearly, (6) is true in this context. It is not permissible, in other words, to choose a point within the line such that the dot is to the right of that point, and then to claim that (6) is false based on this observation. Zwarts \& Winter (2000) account for this by placing a proximity requirement on the point within the line that is chosen to evaluate whether (6) is true. If we are forced to choose the nearest point within the line, the dot will be left of that point; and it is by virtue of this that the dot is left of the entire line-making (6) true in the context of Figure 2.

This treatment of referential NPs is extended by Mador-Haim \& Winter (2007, 2014). The first step in their analysis is to have indefinites denote properties, and the second step is to associate eigenspaces with properties. An entity's eigenspace is the set of all points inhabited by the entity in some spatial domain. And eigenspaces of properties consist of the union of eigenspaces of entities in the extension of the property - a train of thought which is summarized in the Property Eigenspace Hypothesis (Mador-Haim \& Winter 2014).

Property Eigenspace Hypothesis (PEH): A property's eigenspace is the union of eigenspaces for entities in its extension.

With the PEH, we can explain (5) in a way that is similar to how we explain (6). In (5) (in the context of Figure 1) the PEH has it that we are north and not south of a forest because the nearest point in the eigenspace of a forest is such that we are north of that point. Derivational ambiguity between a PEH-based derivation and existential quantification then allows for both the non-existential as well as the existential reading. The story proceeds similarly with (1). Here, in any given context, we are far from a gas station if we are far from the closest point in the eigenspace of a gas station. If we are, then of course we are also far from all other points in that eigenspace-hence the pseudo-universal effect with far from.

In summary, the PEH can account for the non-existential reading we get with (1), and it also explains the non-existential reading of (5), which a derivation involving 


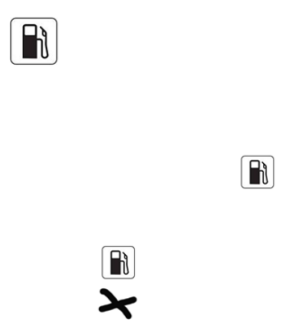

Figure 3 Example stimulus from block I.

decomposition into negated antonyms fails to achieve. Further, the PEH offers theoretical continuity from Zwarts \& Winter's (2000) treatment of referential NPs to a treatment of indefinites in much the same terms. To the extent that the nonexistential interpretations discussed above are secure, we should be willing to endorse the PEH as a theoretical proposal. To test this, an experiment was conducted wherein subjects were presented with stimuli similar to what is shown in Figures 1 and 2.

\section{Method}

\subsection{Participants}

21 Dutch subjects, 16 females and 5 males, aged $18-30$ (mean age $\approx 22.5$ ) participated in the experiment. All participants were either college students or had recently left college. Most had attended or were attending an undergraduate program in the humanities (Liberal Arts and Sciences, Cultural Studies, Languages, Media Studies, etc).

\subsection{Design and procedure}

The experiment consisted of two blocks, both involving an acceptability judgment task. The two blocks were followed by a short interview. In block I, subjects had to give "acceptable"/"unacceptable" judgments on sentence-picture pairs. In block II, subjects had to provide "fair"/"unfair" judgments on pairs consisting of pictures and judgments, made by a fictitious referee, about the content of the picture. A fictitious referee provided judgments which were either consistent with the existential or the non-existential reading, and subjects were asked to judge the acceptability of the referee's judgments. The rationale behind the second block was to provide a more indirect method of eliciting subject judgments, in addition to the direct method from block I.

Target stimuli in block I consisted of a background story and a picture, which 


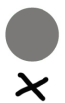

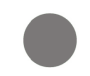

Figure 4 Example stimulus from block II.

together formed the context of interpretation for a sentence whose acceptability subjects had to judge. Throughout block I, background stories were constructed in a way that would make the non-existential reading accessible. At the same time, the pictures presented together with these stories were crafted so as to prime the existential reading. This was meant to keep the non-existential reading available in principle, while also ensuring that the existential reading was not unfairly disadvantaged.

An example of a stimulus from block I is given in Figure 3. In the experiment, Figure 3 was accompanied by the following text (shown on the same screen as Figure $3):^{2}$

We are on a road trip, and we are running low on gas. I check my smartphone to see if there is a gas station nearby. Our position is marked by the cross, and my smartphone displays cheaper gas stations using larger icons.

Subjects were then asked if the following sentence is acceptable: We are far from a gas station. At this point, participants were able to advance to the next screen/stimulus by ticking one of two available boxes through a mouse click: an "acceptable" box or an "unacceptable" box. For the current example, ticking the "acceptable" box would be consistent with an existential reading, and ticking the "unacceptable" box would be consistent with a non-existential reading. The background story was meant to make the non-existential reading accessible, while the existential reading was favored by increasing the size of one of the gas stations that is far from the cross (see Figure 3) - drawing attention to the fact that even though we are close to the nearest gas station, there does exist a gas station such that we are far from it.

In block II, judgments were no longer about sentences but about judgments made by a fictitious referee. An example of a target stimulus from block II is given in Figure 4, which in the experiment was accompanied by the following text (again, on the same screen as Figure 4):

2 The original stimuli were in Dutch and have been translated to English for the purpose of this paper. 
Evidence for non-existential readings of locative indefinites

A general gives the following order to his soldier: "Stay north of a forest!" The soldier positions himself as shown below (i.e. the accompanying picture). The circles are forests, and the position of the soldier is marked by the cross. Later, the general says to his soldier, "You didn't follow my order. You will be punished accordingly." Is the general's statement fair?

As in block I, subjects could advance to the next screen by ticking one of two boxes: a "fair" box or an "unfair" box. Here, the general's judgment that the soldier should be punished can be justified if it is true that the soldier is not positioned north of a forest but south of a forest (the closest one). That is, the general pursues a non-existential strategy, and this is mirrored in his judgment. Hence, ticking "fair" would be consistent with a non-existential reading, and ticking "unfair" would be consistent with an existential reading.

Lastly, a short post-hoc interview was conducted whose goal it was to determine whether there were any pitfalls in the design. Subjects were shown some of the critical stimuli and asked to elaborate on their answers. This also served the purpose of determining whether subjects had been aware of the ambiguity of the stimuli.

\subsection{Stimuli}

In total, there were 18 target stimuli and 18 fillers. Of the 18 targets, 9 were control stimuli. Block I consisted of 8 targets, of which 6 involved indefinite locatives and 2 involved a definite locative (left of/right of the line). The 8 fillers used in block I consisted of pictures of ambiguous-hue objects (e.g., a yellowish-greenish banana), and subjects had to judge the acceptability of sentences in the following format: "The [NOUN] is [ADJECTIVE]" (e.g., "The banana is green"). Block II consisted of 10 targets and 10 fillers. Here, fillers were non-ambiguous pairs of pictures and referee-judgments, and the task was to judge the fairness of the referee's judgment (as with the target stimuli).

The text part of all stimuli was presented in Dutch. Overall, ten PPs were tested with stimuli similar to Figures 3 and 4: far from, close to, inside of, outside of, south of, north of, east of, west of, left of, right of (see the appendix for a list of all stimuli and subject judgments). But not all of these PPs are amenable to a non-existential interpretation. With close to, for example, both a PEH-based and an existential strategy should result in the same judgment: if there is some gas station nearby, then we are also close to the nearest point in the eigenspace of a gas station. Another type of stimulus where both strategies should result in the same answer involves ambiguous PPs, but the accompanying picture is such that either reading should lead to the same judgment. For instance, if the picture is Figure 4 and the sentence to 
be judged is, "We are south of a forest," then both a PEH-based and an existential strategy should result in an "acceptable" judgment. ${ }^{3}$ Factoring out such control stimuli, six PPs were used with stimuli where each answer was consistent with exactly one of the possible readings: far from, outside of, south of, north of, east of, left of.

\section{Results and discussion}

The results for non-control target stimuli are summarized in Table 1. Across all six PPs, $72 \%$ of answers given by subjects correspond to the non-existential reading. Among PPs, there is some variability in the results: the clearest preference for the non-existential reading is attested with far from and outside of. This preference is a bit less pronounced for left of, north of, and south of. Finally, east of is the only PP for which (just about) less than half the answers given correspond to the non-existential reading. It is possible that this variability has to do with the lexical meaning of the prepositions used, with some preferring an existential and others preferring a non-existential reading. But it is also possible that these preferences are a function of the different contexts within which the sentences were presented. Whichever one it is, since both existential and non-existential readings are attested, the results support a double strategy involving derivational ambiguity between the $\mathrm{PEH}$ and existential quantification.

Results for the control stimuli are also generally as expected. Aside from two exceptions, the number of answers which are inconsistent with both the existential and the non-existential reading is below $10 \%$ of answers for a given stimulus. Of the two exceptions, one just barely qualifies as an exception, with only 3 out of 21 answers being inconsistent with either reading. The other exception (6 out of 21 answers inconsistent with either reading) is likely due to an experimental problem. The stimulus in question involves a background story where an art collector orders a painting with a dot that is "right of a circle", but the corresponding picture shows two circles, rather than just one circle. As a result, subjects may simply have rejected the stimulus because the picture contains more circles than what was asked for. ${ }^{4}$ Admittedly, the effect may also have influenced results for the critical left of target, i.e. there may be a small number of PEH-consistent answers which are not due to the non-existential reading. However, the number of affected answers is not larger than 6 , so the effect is relatively small.

The post-hoc interview revealed that subjects were generally able to follow the instructions and had no trouble performing the task. Only 11 subjects seemed to have

3 The PEH would pick the closest forest (the one to the north), and the existential strategy would pick the one forest such that the cross is south of it (again, the one to the north).

4 In fact, this reason was mentioned by two subjects during the post-hoc interview. 
Evidence for non-existential readings of locative indefinites

\begin{tabular}{|c|c|c|c|c|c|c|c|}
\hline Answer & Total & far from & outs. of & left of & north of & south of & east of \\
\hline existential & $28 \%$ & $14 \%$ & $7 \%$ & $24 \%$ & $38 \%$ & $38 \%$ & $55 \%$ \\
\hline non-exist. & $72 \%$ & $86 \%$ & $93 \%$ & $76 \%$ & $62 \%$ & $62 \%$ & $45 \%$ \\
\hline
\end{tabular}

Table 1 Percentages of answers across non-control target stimuli.

been fully aware of the ambiguity of the stimuli. Of the remaining 10 participants, 9 saw the ambiguity of some but not of other stimuli. Only 1 subject was completely unaware of any ambiguity. Overall, subjects seemed to have struggled with stimuli from block II, taking into account not just distance to objects (PEH) and the existence of some object that satisfies the criteria (existential quantification) but also pragmatic factors. For example, one subject remarked that if the person being judged is a soldier, one should be especially harsh in judging the soldier's performance since the military has strict rules. But if the person being judged is an artist, then one should allow the artist more leeway because the rules are less strict with abstract art.

Probably because of the higher processing load and pragmatic factors involved in block II, results for block I are a bit clearer than for block II. For example, even though the spatial configurations of elements in the pictures shown to subjects were similar across blocks, block II trials involving far from elicited more answers that are consistent with the existential reading. On trials involving far from, none of the answers given in block I are consistent with an existential reading, while we find 5 such answers in block II. Presumably, this is experimental noise introduced by pragmatic and processing factors. In future work, it should be sufficient to model experiments on block I.

\section{Conclusion}

The present study showed that the non-existential readings of locative indefinites are available to lay people. There is a strong preference for the non-existential reading with far from and outside of, which is less pronounced for the three other PPs considered. Still, on non-control trials, for all but one PP more than half the answers given are consistent with the non-existential reading. This is evidence in favor of a theoretical account which accommodates the two possible readings via derivational ambiguity between the PEH and existential quantification.

Aapart from explaining the available data, the PEH also offers theoretical elegance in that it is a straightforward extension of the spatial semantics of referential NPs by Zwarts \& Winter (2000). But even if we choose not to endorse the PEH, the present paper provides evidence that indefinites cannot uniformly denote existential quantifiers. Rather, in order to derive the non-existential readings of some locative indefinites, the spatial semantics of indefinites needs to make reference to the no- 
tion of spatial proximity. In this respect, the PEH is one possible way in which a proximity principle can be incorporated into the semantic machinery.

\section{References}

Büring, Daniel. 2007. Cross-polar nomalies. In Semantics and Linguistic Theory (SALT) 17, 37-52. Ithaca, New York: CLC Publications.

Iatridou, Sabine. 2003. Two constructions in Greek and what we can learn from them. In International Conference of Greek Linguistics 6, Rethymno: University of Crete.

Iatridou, Sabine. 2007. A free-choice item hidden in verbal morphology. Unpublished Manuscript.

Mador-Haim, Sela \& Yoad Winter. 2007. Non-existential indefinites and semantic incorporation of PP complements. In Semantics and Linguistic Theory (SALT) 17, 184-201. Ithaca, New York: CLC Publications.

Mador-Haim, Sela \& Yoad Winter. 2014. Far from obvious: the semantics of locative indefinites. Unpublished Manuscript.

Zwarts, Joost \& Yoad Winter. 2000. Vector space semantics: a model-theoretic analysis of locative prepositions. Journal of Logic, Language and Information 9(2). 169-211. doi:10.1023/A:1008384416604.

Robert M. Grimm

Utrecht Institute of Linguistics OTS

Trans 10

3512 JK UTRECHT

r.m.grimm@students.uu.nl

Eva B. Poortman

Utrecht Institute of Linguistics OTS

Trans 10

3512 JK UTRECHT

e.b.poortman@uu.nl
Choonkyu Lee

Utrecht Institute of Linguistics OTS

Trans 10

3512 JK UTRECHT

c.lee@uu.nl

Yoad Winter

Utrecht Institute of Linguistics OTS

Trans 10

3512 JK UTRECHT

y.winter@uu.nl 
Evidence for non-existential readings of locative indefinites

\section{Appendix}

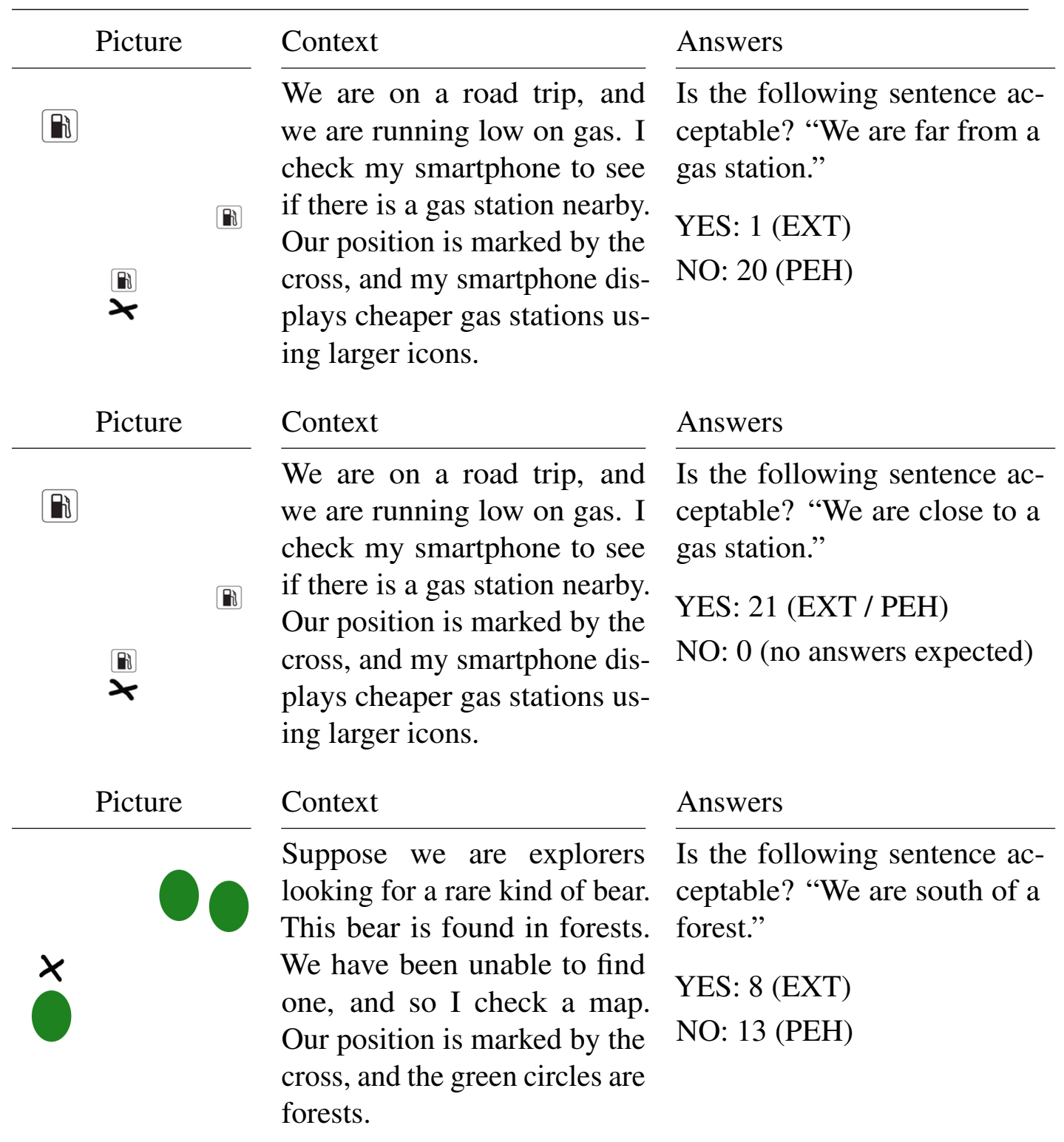

Table 2 All block I stimuli with results — continued on next page. 
Grimm, Lee, Poortman, and Winter

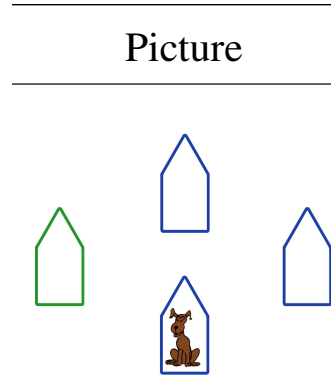

Context

Here is Fido the dog. The green doghouse is Fido's doghouse. The blue doghouses belong to Fido's friends.

\section{Answers}

Is the following sentence acceptable? "Fido is inside of a dog house."

YES: 21 (EXT / PEH)

NO: 0 (no answers expected)

Answers

Is the following sentence acceptable? "Fido is outside of a dog house."

YES: 1 (EXT)

NO: 20 (PEH)

\section{Answers}

Is the following sentence acceptable? "The dot is left of the line."

YES: 20 (PEH)

NO: 1 (no answers expected / noise)

Answers

Is the following sentence acceptable? "The dot is right of the line."

YES: 1 (no answers expected / noise)

NO: 20 (PEH)

Table 2 All block I stimuli with results—continued on next page. 
Evidence for non-existential readings of locative indefinites

\begin{tabular}{llll}
\hline Picture & Context & Answers \\
\cline { 1 - 2 } We travelers crossing a & Is the following sentence ac- \\
desert, and we have become & ceptable? "We are east of an \\
thirsty. I check a map in order & oasis." \\
to locate an oasis. Our posi- & YES: $10(\mathrm{EXT})$ \\
tion is marked by the cross, & NO: $11(\mathrm{PEH})$ \\
and the blue shapes are oases. & NO
\end{tabular}

Table 2 All block I stimuli with results—continued from preceding page.

\begin{tabular}{l}
\hline Picture \\
$\begin{array}{l}\text { Context } \\
\text { A general gives his soldier }\end{array}$ Is the general's statement fair? \\
the following order: "You are \\
to stay north of a forest!" \\
The soldier positions him- FAIR: 13 (PEH) \\
self as shown in the picture. UNFAIR: 8 (EXT) \\
The green circles are forests, \\
and the soldier's position is \\
marked by the cross. Later, \\
the general says to his soldier, \\
"You failed to follow my or- \\
der. You will be punished ac- \\
cordingly!"
\end{tabular}

Table 3 All block II stimuli with results—continued on next page. 
Grimm, Lee, Poortman, and Winter

\begin{tabular}{|c|c|}
\hline Picture & Context \\
\hline & $\begin{array}{l}\text { A general gives his soldier } \\
\text { the following order: "You are } \\
\text { to stay south of a forest!" } \\
\text { The soldier positions him- } \\
\text { self as shown in the picture. } \\
\text { The green circles are forests, } \\
\text { and the soldier's position is } \\
\text { marked by the cross. Later, } \\
\text { the general says to his soldier, } \\
\text { "You failed to follow my or- } \\
\text { der. You will be punished ac- } \\
\text { cordingly!" }\end{array}$ \\
\hline
\end{tabular}

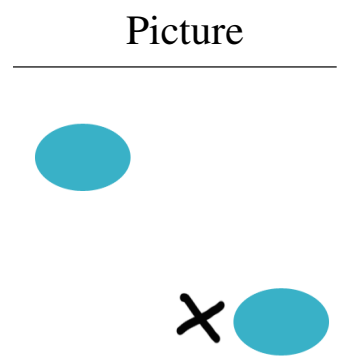

Context

A mother tells her children: "When you go out to play, I want you to stay east of a pond!" The children go out to play. Their position is marked by a cross, and the blue shapes are ponds. Later, the mother says to her children, "You did not do as I asked! You are grounded for the day!"
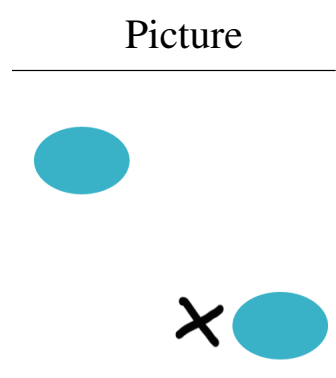

Context

A mother tells her children: "When you go out to play, I want you to stay west of a pond!" The children go out to play. Their position is marked by a cross, and the blue shapes are ponds. Later, the mother says to her children, "You did not do as I asked! You are grounded for the day!"

\section{Answers}

Is the general's statement fair?

FAIR: 3 (no answers expected / noise)

UNFAIR: 18 (PEH / EXT)

Answers

Is the mothers's statement fair?

FAIR: 8 (PEH)

UNFAIR: 13 (EXT)

Answers

Is the mothers's statement fair?

FAIR: 2 (no answers expected / noise)

UNFAIR: 19 (PEH / EXT)

Table 3 All block II stimuli with results—continued on next page. 
Evidence for non-existential readings of locative indefinites

\begin{tabular}{|c|c|c|}
\hline Picture & Context & Answers \\
\hline & $\begin{array}{l}\text { A collector of abstract art or- } \\
\text { ders a painting from his fa- } \\
\text { vorite artist. He tells the artist, } \\
\text { "I would like a painting with } \\
\text { a dot to the left of a circle." } \\
\text { The art collector receives the } \\
\text { painting shown in the picture. } \\
\text { He says to the artist, "This is } \\
\text { not what I ordered!" }\end{array}$ & $\begin{array}{l}\text { Is the art collector's statement } \\
\text { fair? } \\
\text { FAIR: } 16(\mathrm{PEH}) \\
\text { UNFAIR: } 5 \text { (EXT) }\end{array}$ \\
\hline Picture & Context & Answers \\
\hline & $\begin{array}{l}\text { A collector of abstract art or- } \\
\text { ders a painting from his fa- } \\
\text { vorite artist. He tells the artist, } \\
\text { "I would like a painting with } \\
\text { a dot to the right of a circle." } \\
\text { The art collector receives the } \\
\text { painting shown in the picture. } \\
\text { He says to the artist, "This is } \\
\text { not what I ordered!" }\end{array}$ & $\begin{array}{l}\text { Is the art collector's statement } \\
\text { fair? } \\
\text { FAIR: } 5 \text { (EXT) } \\
\text { UNFAIR: } 16(\mathrm{PEH})\end{array}$ \\
\hline Picture & Context & Answers \\
\hline & $\begin{array}{l}\text { You are about to watch a dog } \\
\text { contest. The dog is Fido, and } \\
\text { in order to win the prize, Fido } \\
\text { has to follow the following } \\
\text { rule: "Stay far from a cir- } \\
\text { cle!" You see the situation in } \\
\text { the picture and hear the ref- } \\
\text { eree announcing: "Fido did } \\
\text { not win the prize!" }\end{array}$ & $\begin{array}{l}\text { Is the referee's statement fair? } \\
\text { FAIR: } 16(\mathrm{PEH}) \\
\text { UNFAIR: } 5(\mathrm{EXT})\end{array}$ \\
\hline
\end{tabular}

Table 3 All block II stimuli with results—continued on next page. 
Grimm, Lee, Poortman, and Winter

Context
You are about to watch a dog
contest. In order to win the
prize, Fido has to follow the
rule: "Stay close to a circle!"
You see the situation in the
picture and hear the referee
announcing: "Fido did not
win the prize!"

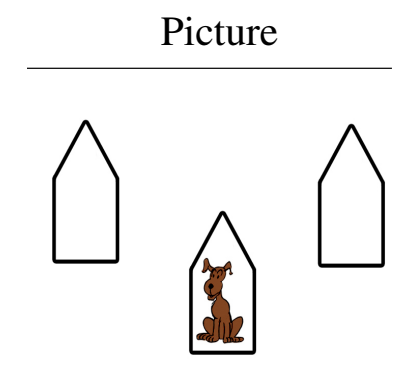

Picture

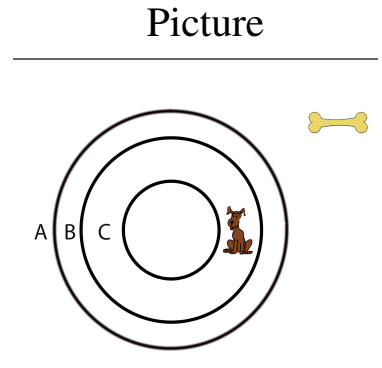

Context

You are about to watch a dog contest. There are some doghouses, and in each doghouse there is a juicy bone. In order to win the prize, Fido has to show restraint and follow the order: "Stay outside of a doghouse!" You see the situation in the picture and hear the referee announcing: "Fido did not win the prize!"

\section{Context}

You are about to watch a dog contest. There are three circles: A, inside of it B, inside of it $\mathrm{C}$. Outside the outermost circle A there is a juicy bone. In order to win the prize, Fido has to show restraint and follow the order: "Stay inside of a circle!" You see the situation in the picture and hear the referee announcing: "Fido did not win the prize!"
Answers

Is the referee's statement fair?

FAIR: 2 (no answers expected / noise)

UNFAIR: 19 (PEH / EXT)

\section{Answers}

Is the referee's statement fair?

FAIR: $19(\mathrm{PEH})$

UNFAIR: 2 (EXT)

\section{Answers}

Is the referee's statement fair?

FAIR: 2 (no answers expected / noise)

UNFAIR: 19 (PEH / EXT)

Table 3 All block II stimuli with results—continued from preceding page. 